has recently been published (ARCRL 10. Pp. $\mathrm{x}+108$. London: Agricultural Research Council. Obtainable from H.M.S.O. 7s. 6d. net). It is the tenth in the serios of reports on the Laboratory's work on radioactivity in the diet. The Radiobiological Laboratory has continued to measure the levels of iodine-131, strontium-89, strontium90 , crsium-137 and barium-140 in foodstuffs in the United Kingdom. The major effort was devotod to milk, samples boing regularly examined from depots which handle more than 40 per cont of Britain's total production. The average ratio of strontium-90/calcium in milk was 12 picocuries/g in 1962 , about $13 \mathrm{pc} / \mathrm{g}$ for the twolve months to the end of March 1963, and about $15 \mathrm{pc} . / \mathrm{g}$ for the twelve months to the end of June. These levels reflect the increased rate of fall-out in 1962, and at the end of the year the twelve-month average was about 20 per cent greater than the previous highest value recordod in 1959 following the 1958 nuclear tests. The average ${ }^{80} \mathrm{Sr} / \mathrm{Ca}$ ratio in the total mixed diet in 1962 was $10 \mathrm{pc} . / \mathrm{g}$, which was about 60 and 10 per cont higher than in 1961 and 1959, respectively, but was still less than 8 per cent of the 'cautionary' working-level of $130 \mathrm{pc} . / \mathrm{g}$ recommended by the Medical Research Council. However, not all the components of the diet reflected the increased rate of fall-out in 1962. In particular, the ${ }^{80} \mathrm{Sr} / \mathrm{Ca}$ ratio for flour was below that for the previous year due to the delay between the harvest of grain and the consumption of the flour. The values rose, however, in the 1962 crop, which did not enter the diet until 1963. The levels of iodine-131 in milk for the first six months of 1963 continued to be below the limit of detection (11 pc./l.). The average for the twelve months to the end of June was below 15 per cent of the Medical Research Council's recommended 'cautionary' level of $130 \mathrm{pc} . / \mathrm{l}$.

\section{One-sided Tolerance Limits and Variables Sampling Plans}

A monograpH recently published by the Sandia Corporation contains a wide selection of tables based on the non-central $t$ distribution (SCR-607: Factors for Onesided Tolerance Limits and for Variables Sampling Plans. By D. B. Owen. Pp. 412. Albuquerque, New Mexico: Sandia Corporation. Available from Office of Technical Services, Department of Commerce, Washington 25, D.C., 1963. 5 dollars). Previous work in this field has thus been extended and, in some cases, corrected. Sam. pling from a normal distribution is considered throughout; the principal tables are designed for use with acceptance procedures (single-samplo variables sampling plans) described in the author's abstract as follows. "The probability is $\gamma$ that at least a proportion $P$ of a normal population is below $\bar{x}+k s$, where $\bar{x}$ has a normal distribution with mean $\mu$ and variance $\sigma^{2} / n$ and $f s^{2} / \sigma^{2}$ has an [independent] chi-square distribution with $f$ degrees of froodom". Typically $\gamma$ and $P$ are fixed according to manufacturer and consumer interests. Values of $k$ are tabulated for suitable values of $\gamma, P$ and the sample sizes $n$ and $f$. Other applications include the power of Student's $t$-test and "expected coverage tolerance limits". The tables are balanced by a valuable commentary. In this, Dr. Owen explains very clearly how to use the tables; he discusses various approximations arising in their construction, and he gives the mathematical derivations on which they rest. Dr. Owen claims that the variables sampling plans discussed are to be preferred, in particular, when the protection of the consumer is of primary interest and the costs of items are high. He does not argue this point, but the reader who feels at all doubtful is free to seek reassurance by sampling the bibliography of some eighty items.

\section{The Night Sky in December}

New moon occurs on Dec. 16d 02h 07m U.T. and full moon on Dec. $30 \mathrm{~d} 11 \mathrm{~h} 04 \mathrm{~m}$. The following conjunctions with the Moon occur: Dec. 18d 14h, Venus 0.5 S.; Dec. 20d $14 \mathrm{~h}$, Saturn $2^{\circ}$ N.; Dec. $24 \mathrm{~d}$ 08h, Jupiter $4^{\circ} \mathrm{N}$. In addition to these conjunctions with the Moon, Mercury is in conjunction with Mars on Dec. 7d 03h, Mercury being $\mathrm{I} \cdot 4^{\circ} \mathrm{S}$., and Mercury with Mars on Dec. $30 \mathrm{~d} 05 \mathrm{~h}$, Mercury being $2^{\circ} \mathrm{N}$. There is a total eclipse of the Moon on December 30, invisible at Greenwich. Mercury is an evening star, but is not well placed for observation. Venus is an evening star, setting at $17 \mathrm{~h} 15 \mathrm{~m}, 17 \mathrm{~h} 40 \mathrm{~m}$ and $18 \mathrm{~h} 30 \mathrm{~m}$ on Dec. 1, 15 and 31 , respectively. Its stellar magnitude is -3.4 ; its distance decreases during the month from 141 to 128 million miles, and the visible portion of the apparent disk decreases from 0.914 to 0.862 . Mars is too close to the Sun for observation. Jupiter sets at $2 \mathrm{~h} 20 \mathrm{~m}$, $1 \mathrm{~h} 20 \mathrm{~m}$ and $0 \mathrm{~h} 25 \mathrm{~m}$ on Decembor 1,15 and 31 , respectivoly. It is in Pisces, its stellar magnitude is -2.2 and its distance from the Earth on December 15 is 425 million miles. Jupiter is stationary on December 6, after which it resumes its eastward motion among the stars. Saturn sets about 4h after the Sun, but conditions for observation are now becoming unfavourable. Occultations of stars brighter than magnitude 6 are as follows, observations being made at Greenwich: Dec. $2 \mathrm{~d}$ Ih $20 \cdot 6 \mathrm{~m}, \zeta$ Tau. $(D)$; Dec. $2 \mathrm{~d} 2 \mathrm{~h}$ $19.0 \mathrm{~m}$, $\zeta$ Tau. $(R)$; Dec. $29 \mathrm{~d} 2 \mathrm{~h} 18.6 \mathrm{~m}, 106$ Tau. $(D) . D$ and $R$ refer to disappearance and reappearance, respectively. The Geminid meteors are active during December 9-14, with maximum on December 13; the radiant is near R.A. $7 \mathrm{~h} 28 \mathrm{~m}$, Dec. $+32^{\circ}$, and conditions for observation are favourable. The Ursid meteors are active during December 20-22, with maximum on December 22; the radiant is near R.A. $14 \mathrm{~h} 28 \mathrm{~m}$, Dec. $+76^{\circ}$, and conditions for observation are favourable. The winter solstice occurs on Dec. 22d 14h.

\section{Announcements}

Prof. C. F. A. Pantrn, professor of zoology in the University of Cambridge, president of the Marine Biological Association and a member of the Nature Conservancy, has been appointed chairman of the newly constituted Trustees of the British Museum (Natural History). Prof. Pantin, who was awarded tho Royal Medal of the Royal Society in 1950, and was President of the Linnean Society from 1958 until 1960, is distinguished for his work in marine biology and experimental zoology, and well known for his interest in providing the broadest possible basis for future specialists.

At a general monthly meeting of the members of the Royal Institution held on November 4, the Right Hon. Lord Brabazon of Tara was appointed honorary professor extraordinary of the Royal Institution. Lord Brabazon has been a Member of the Institution for twenty years and was presidont for fifteen years from 1948 until 1963. He was succeeded as prosident by Lord Fleck.

A Meeting of the Plant Phenolics Group on "Polysaccharides" will be held at the School of Pharmacy, London, on January 7. Further information can be obtained from Mr. A. H. Williams, Research Station, Long Ashton, Bristol.

A colxoquxum on "The Decomposition and Ignition of Peroxides", organized by the Combustion Institute, will be held in the University of Oxford on January 7. Further information can be obtained from Dr. W. G. Parker, Department of Chemistry, College of Advanced Technology, Birmingham 4.

ThF 1964 Winter Gordon Research Conferences on "Polymers" and "Electrochemistry: Electrode Reactions" will be held in Santa Barbara, California, during January 27-February 7. Further information can be obtained from the director of the conferences, Dr. W. George Parks, University of Rhode Island, Kingston, R.I. 